ijlal Erturan,
Inci Meltem Atay*,
Taylan Oksay**,
Vedat Ali Yürekli***,
Arif Demirdaş*,
Ali Murat Ceyhan,
Oya Oylum Argun,
Ahmet Güzel**

Süleyman Demirel Üniversitesi

Tıp Fakültesi, Dermatoloji Anabilim Dalı, Isparta, Türkiye

*Süleyman Demirel Üniversitesi Tıp Fakültesi, Psikiyatri Anabilim Dalı, Isparta, Türkiye

**Süleyman Demirel Üniversitesi Tıp Fakültesi, Üroloji Anabilim Dalı, Isparta, Türkiye

***süleyman Demirel Üniversitesi Tıp Fakültesi, Nöroloji Anabilim Dalı, Isparta, Türkiye

Yazışma Adresi/ Correspondence: jilal Erturan, Süleyman Demirel Üniversitesi Tıp Fakültesi, Dermatoloji Anabilim Dall, Isparta, Türkiye E-posta: ijlalerturan@yahoo.com.tr Geliş Tarihi/Submitted: 13.09.2013 Kabul Tarihi/Accepted: 17.09.2013

@Telif Hakkı 2014 Türk Dermatoloji Derneği Makale metnine www. turkdermatolojidergisi.com web sayfasından ulaşılabilir.

@ Copyright 2014 by Turkish Society of Dermatology - Available on-line at www.turkdermatolojidergisi.com

\section{Kadın Behcet Hastalarında Cinsel Fonksiyonların Değerlendirilmesi}

\author{
Evaluation of Sexual Functions in Female \\ Behçet's Patients
}

\section{Özet}

Amaç: Bu çalışmanın amacı kadınlarda Behçet hastalığının (BH) cinsel fonksiyonlar üzerine etkisi ve cinsel fonksiyonların yaşam kalitesi ve depresyon seviyeleri ile ilişkisini araştırmaktır.

Yöntem: Çalışmaya Behçet hastalığı olan 33 kadın hasta ve 37 sağlıklı kadın dahil edilmiştir. Her iki gruba da Sosyodemografik Veri Formu, Kadın Cinsel Fonksiyon İndeksi (KCFi), Beck Depresyon Ölçeği (BDÖ) ve dermatolojik hastalıklar için hazırlanmış Yaşam Kalite Ölçeği (YKÖ) uygulanmıştır.

Bulgular: Hasta grubunda yaş ortalaması 37,30 $\pm 8,44$ (20-47) yıl ve sağlıkı kontrollerde $37,54 \pm 7,62$ (22-48) yıl olup her iki grup arasında anlamlı fark yoktu $(p=0,902)$. Cinsel disfonksiyon oranı hasta grubunda $(\% 81,8)$ sağlıklı kontrol grubuna $(\% 45,9)$ göre anlamlı şekilde daha yüksekti $(p=0,002)$. Toplam KCFi ve alt parametrelerinin (cinsel arzu, uyarılma, lubrikasyon) puan ortalaması Behçetli hasta grubunda kontrollere göre anlamlı şekilde daha düşüktü. Behçet hasta grubunda BDÖ puanı ile kadın cinsel fonksiyonları ve dermatolojik yaşam kalitesi arasında negatif yönde anlamlı şekilde ilişki mevcuttu.

Sonuç: Bu çalışmada Behçet hasta grubunda cinsel disfonksiyon görülme sıklığının sağlıklı kontrollere göre anlamlı şekilde daha yüksek olduğu sonucuna varılmıştır. Kadın Behçet hastalarında depresyonun bulunmasının yaşam kalitesi ve cinsel fonksiyonlar üzerinde olumsuz etkileri olduğunu düşünmekteyiz.

Anahtar kelimeler: Behçet hastalığı, cinsel disfonksiyon, depresyon, kronik hastalık, yaşam kalitesi, vasküli†

\section{Abstract}

Objective: The aim of this study was to investigate the influence of Behçet's disease (BD) on sexual functioning in female BD patients and the relationship of sexual functions with quality of life (QOL) and depression.

Methods: Thirty-three women with BD and 37 healthy women were included in the study. Sociodemographic data form, The Female Sexual Function Index (FSFI), Beck Depression Inventory (BDI) and QoL Instrument for dermatologic diseases were applied in both groups.

Results: The mean age of patients was 37.30 \pm 8.44 (20-47) years and the mean age of controls was $37.54 \pm 7.62(22-48)$ years and there was no significant difference between the two groups. The rate of sexual dysfunction rate was significantly higher in patients group (81.8\%) than in controls (45.9\%) $(p=0.002)$. The mean FSFI total score and subscale scores (sexual desire, arousal, lubrication) were significantly lower in BD group than those in healthy controls. There was a significant negative correlation between BDI scores with female sexual functions and dermatological QoL in BD patients.

Conclusions: In this study, it was concluded that sexual dysfunction was more frequent among female BD patients than that in healthy controls. Also we suggest that the presence of depression in female BD patients had negative effect on QoL and sexual functions.

Key words: Behçet's disease, sexual dysfunction, depression, chronic disease, quality of life, vasculitis 


\section{Giriş}

Behçet hastalığı (BH) ataklarla seyirli, etyolojisi tam olarak bilinmeyen kronik bir multisistem hastalığıdır. Illk olarak Hulusi Behçet tarafından tekrarlayan oral aft, genital ülserasyon ve hipopyonlu iridosiklit üçlü semptom kompleksi ile tanımlanmıştır. Ancak günümüzde venler, arterler, gastrointestinal sistem, pulmoner sistem, kardiyovasküler sistem ve merkezi sinir sistemi de dahil olmak üzere pek çok sistemin etkilenebildiği kronik, inflamatuar bir vaskülit olduğu anlaşılmıştır (1,2).

Cinsellik, genel sağlığın ayrılmaz parçalarından birini oluşturmakta ve bireyin sağlığını bozan tüm faktörler cinsel yaşamı da olumsuz yönde etkileyebilmektedir (3). Araştırmalar kronik hastalıkların cinsel fonksiyonlar üzerinde olumsuz etkileri olduğunu göstermiştir $(4,5)$. Cinselliğin ve doğurganlığın en üst düzeyde olduğu 20-40 yaşları arasında gözlenen ve vasküler hasar ve fonksiyon kaybına yol açan $\mathrm{BH}$, tüm yönleriyle ele alınsa da diğer kronik hastalıklar ile karşılaştırıldığında cinsel fonksiyonlar üzerindeki etkisini inceleyen çok az sayıda çalışma mevcuttur (6-9).

Çalışmamızda BH'nin, kadın cinsel yaşantısı üzerine etkisinin geçerli bir anket yöntemi olan Kadın Cinsel Fonksiyon İndeksi (KCFI) kullanılarak değerlendirilmesi ve KCFI'nin her bir alt parametresinin yaşam kalitesi ve depresyon ile ilişkisinin araştırılması amaçlanmıştır.

\section{Yöntemler}

Çalışmaya kliniğimizde $\mathrm{BH}$ tanısı almış, cinsel yönden aktif ve katılmayı kabul eden 33 Behçetli kadın hasta ve 37 sağlıklı kontrol dahil edilmiştir. Çalışmaya alınma ölçütleri; hastanın en az 6 aydır BH tanısı olması, okuryazar olması, ölçekleri dolduramayacak düzeyde kognitif fonksiyon bozukluğunun olmaması, nöro-Behçet tanısı almamış olması, en az 1 aydır aktif cinsel hayatının olması, $\mathrm{BH}$ dışında ek bir dermatolojik ve sistemik hastalık öyküsünün bulunmaması, cinsel disfonksiyona sebep olabilecek herhangi bir ilaç kullanmıyor olması ve menopoz öncesi dönemde olmasıdır. Kontrol grubu hasta grubumuzun hastane tabanlı olması sebebi ile hastaneye başvuran hastaların yakınlarından seçilmiş olup yaş, cinsiyet ve eğitim düzeyi açısından olgu grubuna benzer bilinen herhangi bir hastalığı olmayan ve cinsel fonksiyon bozukluğuna sebep olacak herhangi bir tedavi kullanmayan, cinsel olarak aktif, menopoz öncesi dönemdeki bireyleri içermektedir. Hasta grubunda Behçet Hastalığı Anlık Aktivite Formu'na (BHAAF) göre hastalık şiddeti belirlenmiştir (10). Çalışmaya dahil edilme ölçütlerini karşılayan ve katılmayı kabul eden hasta ve kontrol grubuna sosyodemografik veri formu doldurtularak dermatolojik hastalıklar için hazırlanmış Yaşam Kalitesi Ölçeği (YKÖ), KCFI, Beck Depresyon Ölçeği (BDÖ) sırasıyla dermatoloji, üroloji ve psikiyatri kliniklerinde uygulanmıştır. Ayrıca bir nörolog hastaları nöro-Behçet açısından değerlendirmiştir. Çalışma için üniversite yerel etik kurulundan izin alınarak tüm katılımcılara bilgilendirilmiş onam formu imzalatılmıştır.

\section{Veri Toplama Araçları}

\section{Behçet Hastalığı Anlık Aktivite Formu (BHAAF)}

Hastalık aktivitesini dört haftalık klinik özelliklerin hikayesine dayanarak standardize eden bir formdur. Bhakta ve ark. tarafından 1999 yılında oluşturulmuştur. Yüksek puan yüksek hastalık aktivitesini göstermektedir (10).

\section{Yaşam Kalitesi Ölçeği (YKÖ)}

Gürel ve ark. tarafından Türk toplumunda dermatolojik hastalıklarda yaşam kalitesini ölçmek için geliştirilmiş 11 soruluk bir ölçektir. Ölçekten alınabilecek puan 0-44 arasında değişebilmekte yüksek puan düşük yaşam kalitesini göstermektedir (11).

\section{Kadın Cinsel Fonksiyon İndeksi (KCFi)}

Rosen ve ark. tarafından geliştirilen ve kadın cinsel fonksiyonunun altı alt boyutunu sorgulayan bir sorgulama formudur (12). Alınan yüksek puanlar yüksek cinsel fonksiyonu gösterirken, düşük puanlar düşük cinsel fonksiyonu göstermektedir. KCFI'nin Türkçe geçerlilik ve güvenilirliği Öksüz ve Malhan tarafından yapılmıştır (13). Wiegel 2005 yılında ölçeğin kesme puanını 26,55 olarak belirlemiş ve $26,55^{\prime}$ in altındaki değerler cinsel disfonksiyon olarak değerlendirilmiştir (14).

\section{Beck Depresyon Ölçeği (BDÖ)}

Beck tarafından erişkinlerde depresyon riskini, depresif belirtilerin düzeyini ve şiddet değişimini ölçmek üzere geliştirilmiştir (15). Türkçe geçerlik ve güvenirlik çalışması Hisli tarafından yapılmış ve kesme puanı 17 olarak belirlenmiştir (16).

\section{İstatistiksel Değerlendirme}

Bu çalışmada elde edilen verilerin istatistiksel incelenmesi SPSS Windows 15.0 istatistik programı ile yapılmıştır. Değişkenlerin normal dağılıma uygunluğu KolmogorovSmirnov testi ve histogramlar incelenerek değerlendirilmiştir. Karşılaştırmalarda bağımsız gruplarda t testi, Mann Whitney $\mathrm{U}$ testi ve Ki kare testi kullanılmıştır. Her iki değişkenin de normal dağıldığı durumlarda korelasyon katsayıları ve istatistiksel anlamlılıkları Pearson testi ile hesaplanmışken iki değişkenden en az birinin normal dağılmadığı durumlarda korelasyon katsayıları ve istatistiksel anlamlılıkları Spearman testi ile hesaplanmıştır. Anlamlılık için sınır değer olarak $p<0,05$ kabul edilmiştir.

\section{Bulgular}

Çalışmaya 33 kadın Behçet hastası ve 37 sağlıklı kontrol dahil edilmiştir. Çalışmaya alınan Behçet hastalarının ortalama yaşı 37,30 $\pm 8,44$ (20-47), kontrol grubunun ortalama yaşı $37,54 \pm 7,62$ (22-48) olup iki grup arasında anlamlı fark yoktu $(p=0,902)$. Çalışmaya dahil edilen hasta ve kontrol grubu arasında eğitim düzeyi açısından anlamlı fark yoktu $(p=0,398)$.

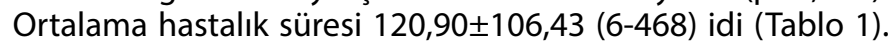
Hastalardan 18'i $(\% 54,54)$ hastalığına yönelik olarak herhangi bir ilaç kullanmazken, 15'i $(\% 45,45)$ kolşisin (150 mg/gün) kullanmakta idi. İlaç kullanan ve kullanmayanlar hastalar arasında toplam KCFİ ve alt parametreler ortancaları arasında anlamlı fark yoktu (toplam KCFI $p=0,086$, cinsel arzu $p=0,845$, uyarılma $p=0,073$, lubrikasyon $p=0,244$, orgazm $p=0,126$, tatmin $p=0,630$, ağrı $p=0,215)$.

Çalışmamızda ortalama KCFi toplam puanı hasta grubunda kontrol grubuna göre anlamlı olarak daha düşüktü (sırasıyla KCFİ toplam puanı ortalama \pm standart sapmaları, 21,56 $\pm 5,25$, $25,81 \pm 5,25$ bağımsız gruplarda $t$ testi $p=0,011)$. Hasta 
grubunda cinsel disfonksiyon oranı kontrol grubuna göre anlamlı olarak daha yüksekti (sırasıyla cinsel disfonksiyon yüzdesi, \%81,8, \%45,9, Ki kare testi $p=0,002$ ).

Hasta ve kontrol grubu arasında KCFI alt parametrelerinden ortalama cinsel arzu puanı açısından farklılık olup hasta grubunda kontrol grubuna göre anlamlı şekilde daha düşüktü (sırasıyla cinsel arzu puanı ortalama \pm standart sapmaları, $2,90 \pm 1,15,3,51 \pm 1,17$ bağımsız gruplarda t testi $p=0,032$ ). Hasta ve kontrol grubu arasında KCFi alt parametrelerinden ortalama uyarılma puanı açısından fark olup hasta grubunda kontrol grubuna göre anlamlı olarak daha düşüktü (sırasıyla uyarılma puanı ortalama \pm standart sapmaları, 3,03 $\pm 1,03$, $3,91 \pm 1,38$ bağımsız gruplarda t testi $p=0,004)$. Hasta ve kontrol grubu arasında KCFI alt ölçeklerinden ortalama lubrikasyon puanı açısından anlamlı farklılık olup hasta grubunda kontrol grubuna göre daha düşüktü (sırasıyla lubrikasyon puanı ortalama \pm standart sapmaları, 3,83 $\pm 1,28,4,5 \pm 1,29$ bağımsız gruplarda t testi $p=0,035$ ) (Tablo 2 ).

Depresyonu olanlarda toplam KCFI ortanca puanı kontrollere göre anlamlı şekilde daha düşüktü $(p=0,021$, Mann Whitney U testi). Depresyonu olanlarda yaşam kalitesi depresyonu olmayanlara göre anlamlı şekilde daha düşüktü $(p=0,049$, Mann Whitney $U$ testi). Cinsel disfonksiyonu olanlar ve olmayanların ortanca puanları karşılaştırıldığında cinsel disfonksiyonu olanlarda yaşam kalitesinin anlamlı şekilde bozulduğu saptanmıştır ( $p=0,011$, Mann Whitney U testi). Genital ülseri olanlarda ortalama arzu puanının genital ülseri olmayanlara göre anlamlı şekilde yüksek olduğu saptanmış olup ( $p=0,040$, Mann Whitney $U$ testi) toplam KCFI puanı ve diğer alt parametreler açısından anlamlı farklılık mevcut değildi.

\section{Korelasyonlar}

BDÖ puanı ile total KCFI puanı arasında negatif yönde anlamlı korelasyon mevcuttu ( $r=-0,556, p=0,001)$. BDÖ puanı ile cinsel arzu puanı arasında negatif yönde anlamlı korelasyon mevcuttu $(r=-0,373, p=0,032)$. BDÖ puanı ile tatmin puanı arasında negatif yönde anlamlı korelasyon mevcuttu $(r=-0,639, p<0,001)$. Hastalık süresi ile cinsel arzu $(r=-0,405, p=0,018)$ ve lubrikasyon puanları arasında negatif yönde anlamlı korelasyon mevcuttu ( $r=-0,480 p=0,005)$. YKÖ puanı ile toplam KCFI puanı arasında negatif yönde anlamlı korelasyon mevcuttu ( $r=-0,403, p=0,020)$ (Tablo 3).

\section{Tartışma}

Çalışmamızda BH olan kadınlarda depresyon düzeylerinin sağlıklı kontrollere göre anlamlı şekilde arttığı, yaşam kalitesi ve seksüel fonksiyonları olumsuz yönde etkilediği ve bu hastalarda cinsel disfonksiyon oranının sağlıklı kontrollere göre anlamlı şekilde yüksek olduğu bulunmuştur.

Cinsel disfonksiyon tüm dünyada kadınların \%20-\%50'sini ilgilendiren yaygın bir sorundur ve kadınlarda görülme sıklığı erkeklere göre daha yüksektir $(17,18)$. Laumann ve ark. 1859 yaş arası kadınlarda cinsel disfonksiyon görülme oranını \%43 olarak rapor etmiş̧lerdir (19). Kronik hastalık varlığında cinsel fonksiyonlar olumsuz yönde etkilenmektedir $(4,20,21)$. Çalışmamızda BH bulunan kadınlarda cinsel disfonksiyon oranı \%81,8 olup literatür ile benzer şekilde BH olan kadınlarda KCFi ortalama puanının sağlıklı kontrollere göre anlamlı şekilde düşük bulunmuştur $(7,9)$. Behçet hastaları ile yapılan çalışmalarda hastalık sonrası dönemde cinsel yaşantının ve cinsel doyumun olumsuz yönde etkilendiği bildirilmiştir $(6,22)$. Özdemir ve ark. kadın Behçet hastalarında cinsel disfonksiyon oranını \%89,8 olarak rapor etmişken (6) Gül ve ark. bu oranı \%96,2 olarak bildirmiş̧lerdir (22). Çalışmamızdan ve literatürden elde edilen veriler doğrultusunda kadın cinsiyet sebebi ile mevcut olan cinsel disfonksiyon riskinin $\mathrm{BH}$ sebebi ile hemen hemen ikiye katlandığı söylenebilir.

Çalışmamızda Behçetli olgularda diğer kronik hastalıklarla benzer şekilde cinsel arzu, uyarılma ve lubrikasyon puanları ortalaması kontrollere göre anlamlı şekilde düşmüştü $(20,23)$. Koçak ve ark. çalışmalarında kadın Behçet hastalarında en sık rastlanan cinsel sorunların sırasıyla lubrikasyon $(\% 50,79)$, uyarılma $(\% 49,69)$ ve cinsel arzu $(\% 45,1)$ düzeylerinde azalma olduğunu bildirmişlerdir (7).

BH'de vasküler patolojiler genital kanlanmayı olumsuz yönde etkileyerek cinsel fonksiyonlarda bozulmalara sebep olabilmektedir. Aksu ve ark. nörolojik tutulumu olmayan ve venöz kaçağa bağlı kavernöz venlerde oluşan tromboz sonucu erektil disfonksiyonu olan 2 olgu bildirmişler ve BH'de vasküler patolojilerin cinsel disfonksiyona sebep olabileceğini

Tablo 1. Hasta ve kontrol grubunun tanımlayıcı ve klinik özellikleri

\begin{tabular}{|c|c|c|c|}
\hline & Hasta $(n=33)$ & Kontrol $(\mathrm{n}=37)$ & p değeri \\
\hline Yaş, ortalama \pm SS & $37,30 \pm 8,44$ & $37,54 \pm 7,62$ & $0,902^{* *}$ \\
\hline Okur yazar & $3(\% 9,1)$ & $6(\% 16,2)$ & \\
\hline İlköğretim & $27(\% 81,8)$ & $24(\% 64,9)$ & $0,398^{*}$ \\
\hline Üniversite & $2(\% 6,1)$ & $3(\% 8,1)$ & \\
\hline Behçet hastalığı aktivite skoru, ortalama \pm SS, (min-max) & $4,06 \pm 2,16(0-7)$ & - & - \\
\hline Behçet hastalığı süresi, ay, ortalama \pm SS, (min-max) & $120,90 \pm 106,47(6-468)$ & - & - \\
\hline Behçet hastalığı yaşam kalitesi, ortalama \pm SS & $15,96 \pm 10,34$ & $1,13 \pm 2,04$ & $\mathrm{p}<0,001^{\star *}$ \\
\hline Beck depresyon ölçeği, ortalama \pm SS & $17,30 \pm 14,22$ & $10,29 \pm 8,72$ & $0,014^{* *}$ \\
\hline
\end{tabular}


rapor etmişlerdir (24). Kadınlarda vasküler hasar nedeniyle pelvik kan akımının azalması, vajinal duvar ve klitoral düz kas dokusunda fibrozis oluşumuna neden olmakta ve gelişen düz kas fibrozisi nedeni ile kadınlar cinsel ilişkide kuruluk ve uyarılma aşamasının olumsuz etkilenmesine bağlı olarak cinsel isteksizlik, ağrı ve orgazm olamama gibi sorunlar yaşayabilmektedirler $(3,25,26)$. Son yıllarda vajinal, klitoral ve kavernöz dokuda nitrik oksid (NO) gibi nörotransmitterler tanımlanmıştır. NO'nun genital bölgedeki vasküler dokuların düz kaslarında relaksasyon yaparak genital bölgeye kan akımını arttırarak cinsel fonksiyonları düzenlediği bildirilmiştir (26). BH'de dokuda ve kanda azalan NO seviyeleri vasküler hasar ve vajinal kan akımının azalması sebebi ile cinsel fonksiyon bozukluklarına zemin hazırlayabilir (27-29).

Kronik hastalıklarda uzamış hastalık süresi de cinsel seksüel fonksiyon bozukluklarına eşlik edebilmektedir (30). Çalışmamızda hastalık süresi uzadıkça cinsel arzu ve lubrikasyon düzeylerinin azaldığı bulunmuştur. Bu beklenen bir durum olup hastalık süresi uzadıkça ortaya çıkan sistemik ve psikiyatrik komplikasyonlar cinsel fonksiyon bozukluklarına zemin hazırlayabilir. Nitekim multipl sklerozlu ve diyabetli hastalarda hastalık süresinin cinsel disfonksiyonu belirleyici faktörlerden biri olduğu bildirilmiştir $(31,32)$.

Depresyon, anksiyete, benlik saygısı, vücut imajı gibi psikolojik faktörler ve stres kadınlarda cinsel fonksiyonları olumsuz yönde etkileyebilmektedir (3,30,33,34). Çalışmamızda literatür ile uyumlu olarak Behçetli kadın hasta grubunda BDÖ puan ortalamasının kontrollere göre anlamlı şekilde daha yüksek olduğu bulunmuş $(7,9)$ ve depresyon varlığı ile cinsel fonksiyonları yansıtan toplam KCFi puanının anlamlı şekilde düştüğü saptanmıştır. Literatürde kadın ve erkek Behçet hastalarında cinsel fonksiyonlar ile BDÖ puanının negatif korele olduğu bildirilmiştir $(7,8,22)$. Ayrıca KCFi alt parametreleri emosyonel ve psikolojik faktörlerden de

\begin{tabular}{|c|c|c|c|}
\hline & Hasta $(n=33)$ & Kontrol (n=37) & ${ }^{*} \mathbf{p}$ değeri \\
\hline Arzu & $2,90 \pm 1,15$ & $3,51 \pm 1,17$ & 0,032 \\
\hline Uyarılma & $3,03 \pm 1,03$ & $3,91 \pm 1,38$ & 0,004 \\
\hline Lubrikasyon & $3,83 \pm 1,28$ & $4,5 \pm 1,29$ & 0,035 \\
\hline Orgazm & $4,04 \pm 2,43$ & $4,42 \pm 1,45$ & 0,420 \\
\hline Tatmin & $4,12 \pm 1,34$ & $4,55 \pm 1,53$ & 0,219 \\
\hline Ağrı & $4,32 \pm 2,61$ & $4,32 \pm 1,63$ & 0,995 \\
\hline Toplam & $21,56 \pm 5,25$ & $25,81 \pm 7,93$ & 0,011 \\
\hline \multicolumn{4}{|c|}{${ }^{*}$ Bağımsız gruplarda $\mathrm{T}$ testi } \\
\hline
\end{tabular}

etkilenebilmektedir $(7,35)$. Çalışmamızda Koçak ve ark.'nın çalışmasında benzer şekilde BDÖ puanı arttıkça cinsel arzu puanının anlamlı şekilde düştüğü saptanmıştır (7).

BH'de yaşam kalitesinin başta anksiyete ve depresyon olmak üzere ruhsal belirtilerden anlamlı şekilde etkilendiği bildirilmiştir (36). Çalışmamızda depresyonu olan Behçet hastalarında yaşam kalitesinin depresyonu olmayanlara göre anlamlı şekilde daha düşük olduğu bulunmuştur. Yine literatür ile uyumlu olarak cinsel disfonksiyonu olan hastalarda yaşam kalitesi anlamlı şekilde düşük bulunmuş olup yaşam kalitesi bozuldukça toplam KCFi puanı da düşmekte idi (37). Ermertcan ve ark. çalışmalarında psoriazis ve nörodermatitte yaşam kalitesindeki bozulmanın kadın cinsel fonksiyonunu olumsuz yönde etkilediğini rapor etmişlerdir $(20,38)$. Sampogna psoriazisli hastalarının \%71,3'ünde bozulan yaşam kalitesi nedeni ile cinsel disfonksiyon bildirmiştir (21).

Pek çok çalışmada Behçet hastalarında genital ülser varlığı ile cinsel disfonksiyon arasında anlamlı bir ilişki bildirilmemiştir (69). Biz de literatür ile uyumlu olarak genital ülseri olan hastalar ile genital ülseri olmayan hastalar arasında toplam cinsel fonksiyon puanı açısından anlamlı farklılık saptamazken genital ülseri olanlarda olmayanlara göre cinsel arzu puanını anlamlı olarak daha düşük saptadık. Koçak ve ark. da genital ülseri bulunan kadınların \%49,1'inde cinsel arzu puanında anlamlı düşüklük saptamışlardır (7). Çalışmamızda genital ülseri bulunan hastalarda genital ülser bulunmayan hastalara göre toplam KCFI puanı ve alt parametreleri arasında fark olmamasına rağmen cinsel arzu puanının düš̈̈k olması, genital ülseri bulunan kadının eşi tarafından çekici bulunmama düşüncesinin psikolojik olarak cinsel arzu puanını etkilemesi ile ilişkili olabilir.

Hastalıkla ilgili ilaç kullanımları cinsel sorunlara yol açabilmektedir. Kolşisinin miyopati ve nöropati yaparak cinsel disfonksiyona sebep olduğu bildirilmiştir (39). Hastalarımızın $\% 45,45^{\prime}$ i kolşisin kullanmakta olup literatür ile uyumlu olarak kolşisin kullanan ve kullanmayan hastalar arasında toplam cinsel fonksiyon ve alt parametreleri açısından anlamlı farklııık yoktu $(7,8)$. Nörolojik tutulum (nöro-Behçet) cinsel sorunlara yol açabilmekle birlikte çalışmamızda nörolojik tutulumu olan hastaların çalışma dışı bırakılmıştır.

Çalışmaya dahil edilme kriterleri sebebi ile sınırlı sayıda hastanın çalışmaya alınması kısıtlılıklarımız arasındadır. Buna karşın KCFi, BDÖ puanlarının birlikte değerlendirildiği çalışmalar olması yanında bu parametrelere ek olarak hastalık aktivitesi ve dermatolojik yaşam kalitesinin değerlendirilmesi çalışmamızın güçlü yanını oluşturmaktadır.

\section{Sonuç}

Çalışmamızın sonuçları kadın Behçet hastalarında depresyon varlığı ile yaşam kalitesi ve cinsel fonksiyonların anlamlı

Tablo 3. Çalışmadan elde edilen verilerin korelayon analiz sonuçları

\begin{tabular}{|l|l|l|l|l|l|}
\hline & $\begin{array}{l}\text { Arzu } \\
(\mathbf{r} \text { değeri) }\end{array}$ & $\begin{array}{l}\text { Lubrikasyon } \\
(\mathbf{r} \text { değeri) }\end{array}$ & $\begin{array}{l}\text { Tatmin } \\
(\mathbf{r} \text { değeri) }\end{array}$ & $\begin{array}{l}\text { Ağri } \\
(\mathbf{r} \text { değeri) }\end{array}$ & $\begin{array}{l}\text { KCFI toplam puan } \\
(\mathbf{r} \text { değeri) }\end{array}$ \\
\hline Hastalık süresi & $-0,405^{*}$ & $-0,480^{* *}$ & $-0,136$ & $-0,137$ & $-0,338$ \\
\hline Yaşam kalite ölçek puanı & $-0,242$ & $-0,148$ & $-0,090$ & $0,500^{* *}$ & $-0,403^{*}$ \\
\hline Beck depresyon ölçek puanı & $-0,373^{*}$ & $-0,263$ & $-0,639^{* * *}$ & $-0,288$ & $-0,556^{* *}$ \\
\hline${ }^{*} \mathrm{p}<0,05^{* *} \mathrm{p}<0,01^{* * *} \mathrm{p}<0,001$ & \multicolumn{5}{|l}{} \\
\hline
\end{tabular}


şekilde bozulduğunu göstermiş̧tir. Kronik hastalıklardan biri olan BH'nin tedavisine multidisipliner yaklaşılarak hastalığın psikiyatrik durum ve cinsel fonksiyonlar üzerine etkileri de göz önünde bulundurulmalıdır. BH'de var olan depresif durumun tedavisi ile yaşam kalitesinin ve cinsel fonksiyonların düzelebileceği düşünülmektedir. Bu hastalarda depresif durum ve cinsel fonksiyonlar ile ilgili sorunları belirlemeye yönelik olarak daha geniş serili, prospektif çalışmalara ihtiyaç olup bu çalışmaların verileri ile Behçet hastalarında cinsel fonksiyonlara yönelik olarak gerekli destek verilebilecektir.

\section{Kaynaklar}

1. Arca E, Gür AR. Behçet hastalı̆ı. T Klin J Med Sci 2003;3:261-8.

2. Alpsoy E. Behçet hastalığı: Etyoptogenezde güncel bilgiler. Turk J Dermatol 2013;7:41-5.

3. Kütmeç C. Kadınlarda cinsel fonksiyon bozukluğu ve hemşirelik bakımı. Fırat Sağlık Hizmetleri Dergisi 2009;4:111-36.

4. Cebeci SA, Genç $\mathrm{H}$, Erdem HR, ve ark. Romatoid artritli kadın hastalarda seksüel disfonksiyonun değerlendirilmesi. Türk Fiz Tıp Rehab Derg 2012;58:36-46.

5. AT Ermertcan. Sexual dysfunction in dermatological diseases. J Eur Acad Dermatol Venereol 2009;23:999-1007.

6. Özdemir L, Kalyoncu U, Akdemir N. Behçet hastalığında cinsel sorunlar ve etkileyen faktörlerin değerlendirilmesi. Trakya Univ Tipm Fak Derg 2010;27:238-42.

7. Koçak M, Başar MM, Vahapoğlu G, et al. The effect of Behçet's disease on sexual function and psychiatric status of premenopausal women. J Sex Med 2009;6:1341-8.

8. Hiz O, Ediz L, Gülcü E, Tekeoglu I. Effects of Behçet's disease on sexual function and psychological status of male patients. J Sex Med 2011;8:142633.

9. Yetkin DO, Celik O, Hatemi G, Kadioglu P. Sexual dysfunction and depression in premenopausal women with mucocutaneous Behçet's disease. Int J Rheum Dis 2013;16:463-8.

10. Bhakta BB, Brennan $P$, James $T E$, et al. Behcet's disease: evaluation of a new instrument to measure clinical activity. Rheumatol 1999;38:728-33.

11. Gurel MS, Yanik M, Şimşek Z, et al. Quality of life instrument for Turkish people with skin diseases. Int J Dermatol 2005;44:933-8.

12. Rosen R, Brown C, Heiman J, et al. The Female Sexual Function Index (FSFI): a multidimensional self-report instrument for the assessment of female sexual function. J Sex Marital Ther 2000;26:191-208.

13. Oksuz $E$, Malhan $S$. Reliability and validity of female sexual function index in Turkish population. Sendrom 2005;17:54-8.

14. Wiegel M, Meston C, Rosen R. The Female Sexual Function Index (FSFI): Cross-Validation and Development of Clinical Cutoff Scores. J Sex Marital Ther 2005;31:1-20.

15. Beck AT, Jard $\mathrm{CH}$, Mendelson $\mathrm{M}$, et al. An inventory for measuring depression. Arch Gen Psychiatry 1961;4:561-71.

16. Hisli N. Beck Depresyon Envanterinin üniversite öğrencileri için geçerliliği, güvenirliği. Psikoloji Dergisi 1989;7:3-13.
17. Güvel S. Yaycıoğlu Ö, Bağış T, ve ark. Evli kadınlarda cinsel fonksiyonlara etkin faktörler. Türk Üroloji Dergisi 2003;29:43-8.

18. Cabral PU, Canário AC, Spyrides MH, et al. Determinants of sexual dysfunction among middle-aged women. Int J Gynaecol Obstet 2013;120:271-4.

19. Laumann EO, Paik A, Rosen RC. Sexual dysfunction in the United States: prevalence and predictors. JAMA 1999;281:537-44.

20. Türel Ermertcan A, Temeltaş G, Deveci A, et al. Sexual dysfunction in patients with psoriasis. J Dermatol 2006;33:772-8.

21. Sampogna F, Gisondi P, Tabolli S, Abeni D; IDI Multipurpose Psoriasis Research on Vital Experiences investigators. Impairment of sexual life in patients with psoriasis. Dermatology 2007;214:144-50.

22. Gül IG, Kartalcı S, Cumurcu BE, et al. Evaluation of sexual function in patients presenting with Behçet's disease with or without depression. J Eur Acad Dermatol Venereol 2013;27:1244-51.

23. Doruk H, Akbay E, Cayan S, et al. Effect of diabetes mellitus on female sexual function and risk factors. Arch Androl 2005;51:1-6.

24. Aksu K, Keser G, Günaydin G, et al. Erectile dysfunction in Behçet's disease without neurological involvement: two case reports. Rheumatology (Oxford) 2000;39:1429-31.

25. Khalifé S, Binik YM, Cohen DR, Amsel R. Evaluation of clitoral blood flow by color Doppler ultrasonography. J Sex Marital Ther 2000;26:187-9.

26. Incesu C. Cinsel işlevler ve cinsel işlev bozuklukları. Klinik Psikiyatri 2004;3:313.

27. Onur E, Kabaroglu C, Inanir I, et al. Oxidative stress impairs endothelial nitric oxide levels in Behçets' disease. Cutan Ocul Toxicol 2011;30:217-20.

28. Orem A, Vanizor B, Cimşit $G$, et al. Decreased nitric oxide production in patients with Behçet's disease. Dermatology 1999;198:33-6.

29. Senturk MU, Senturk UK, Basak PY, et al. Serum and skin nitrite levels in patients with Behcet's disease. J Eur Acad Dermatol Venereol 2003;17:614-5.

30. Schouffoer AA, van der Marel J, Ter Kuile MM, et al. Impaired sexual function in women with systemic sclerosis: a cross-sectional study. Arthritis Rheum 2009;61:1601-8.

31. Mohammadi K, Rahnama P, Moayed Mohseni S, et al. Determinants of sexual dysfunction in women with multiple sclerosis. BMC Neurol 2013;13:83.

32. Fatemi SS, Taghavi SM. Evaluation of sexual function in women with type 2 diabetes mellitus. Diab Vasc Dis Res 2009;6:38-9.

33. Dunn KM, Croft PR, Hackett Gl. Association of sexual problems with social psychological, and physical problems in men and women: a cross sectional population survey. J Epidemiol Community Health 1999;53:144-8.

34. Morales MG, Rubio JC, Peralta-Ramírez M, et al. Impaired sexual function in women with systemic lupus erythematosus: a cross-sectional study. Lupus 2013;22:987-95.

35. Basson R, Leiblum S, Brotto L, et al. Revised definitions of women's sexual dysfunction. J Sex Med 2004;1:40-8.

36. Uğuz F, Dursun R, Kaya N, Çilli AS. Behçet hastalarında ruhsal belirtiler ve yaşam kalitesi. Anadolu Psikiyatri Dergisi 2006;7:133-9.

37. Park H, Yoon HG. Menopausal symptoms, sexual function, depression, and quality of life in Korean patients with breast cancer receiving chemotherapy Support Care Cancer 2013;21:2499-507.

38. Ermertcan AT, Gencoglan G, Temeltas G, et al. Sexual dysfunction in female patients with neurodermatitis. J Androl 2011;32:165-9.

39. Kuncl RW, Duncan G, Watson D, et al. Colchicine myopathy and neuropathy. N Engl J Med 1987;316:1562-8. 